\title{
Comparison of intravaginal progesterone gel and intramuscular 17- $\alpha$-hydroxyprogesterone caproate in luteal phase support
}

\author{
FUNDA SATIR, TAYFUN TOPTAS, MURAT INEL, MUNIRE ERMAN-AKAR and OMUR TASKIN \\ Department of Obstetrics and Gynaecology, Akdeniz University Hospital, Antalya 07070, Turkey
}

Received December 22, 2012; Accepted March 26, 2013

DOI: $10.3892 /$ etm.2013.1049

\begin{abstract}
The main objective of this study was to compare the pregnancy rates of intramuscular (IM) 17- $\alpha$-hydroxyprogesterone caproate (17-HPC) and intravaginal (IV) progesterone gel administration in in vitro fertilization-embryo transfer (IVF-ET) cycles. The IM 17-HPC and IV progesterone groups included 632 (66.4\%) and 320 (33.6\%) women undergoing the first cycles of IVF-ET treatment, respectively. Multivariate analyses annotated for all potential confounders showed that the use of IV progesterone retained a predictive value for the total $\beta$-human chorionic gonadotropin (hCG) positivity and clinical pregnancy rates [adjusted odds ratio (OR), 1.97; 95\% confidence interval (CI), 1.28-3.03; P=0.002; and OR, 1.66; 95\% CI, 1.07-2.60; $\mathrm{P}=0.03$, respectively]. However, biochemical and on-going pregnancy rates did not differ significantly between the groups $(\mathrm{OR}, 1.85 ; 95 \% \mathrm{CI}, 1.00-3.41 ; \mathrm{P}=0.05$; and $\mathrm{OR}$, $1.43,95 \%$ CI, 0.89-2.30; $\mathrm{P}=0.14$, respectively). Luteal phase support (LPS) with IV progesterone gel in comparison with IM 17-HPC appears to be associated with higher clinical pregnancy rates in IVF-ET cycles. However, this benefit is clinically irrelevant in terms of on-going pregnancy outcomes.
\end{abstract}

\section{Introduction}

Ovarian hyperstimulation procedures during in vitro fertilization-embryo transfer (IVF-ET) cycles stimulate the formation of multiple follicles and corpora lutea. However, the quantity of endogenous progesterone produced by multiple corpora lutea is not sufficient for the implantation and the continuation of early pregnancy (1-3). There are several mechanisms leading to luteal phase defect in IVF-ET cycles. The use of gonadotropin-releasing hormone $(\mathrm{GnRH})$ analogs in IVF-ET cycles suppresses the production of endogenous gonadotro-

Correspondence to: Dr Tayfun Toptas, Department of Obstetrics and Gynaecology, Akdeniz University Hospital, Antalya, Turkey

E-mail:drttoptas@gmail.com

Key words: intravaginal progesterone gel, 17- $\alpha$-hydroxyprogesterone, luteal phase support pins. This, in particular due to the suppression of luteinizing hormone (LH), halts the activity of the corpus luteum (4). Furthermore, GnRH antagonists may also shorten the luteal phase. Human chorionic gonadotropin (hCG) has a negative feedback on the pituitary gland, and causes pituitary suppression during the luteal phase (5). Thus, it is necessary to use exogenous progesterone to support the luteal phase in IVF-ET cycles due to the insufficient corpus luteum function $(1-3,6)$. In addition, the American Society for Reproductive Medicine (ASRM) Position Statement recommends progesterone supplementation in IVF cycles due to the higher pregnancy rates achieved by progesterone administration compared with placebo or no treatment (1).

Among the routes of progesterone administration, intravaginal (IV) and intramuscular (IM) routes are currently the most commonly used (7,8). Although IM forms of progesterone achieve higher serum progesterone levels, IV administration provides higher local tissue levels in the endometrium (9). A previously published meta-analysis demonstrated the benefit of IM over IV progesterone administration for luteal phase support (LPS) on pregnancy outcomes (6). However, another meta-analysis including additional randomized controlled studies showed that the effects of IV and IM forms of progesterone on pregnancy end-points were comparable (10). Notably, the most effective route of progesterone administration in LPS remains to be clarified.

The aim of the current study was to compare the effects of IM and IV gel forms of progesterone used for LPS following IVF-ET on clinical and on-going pregnancy rates.

\section{Patients and methods}

Patients. This retrospective single centre study was undertaken in subjects who received IVF-ET treatment between October 1999 to August 2009 in the Department of Obstetrics and Gynaecology, Centre for Assisted Reproductive Techniques and Infertility, Akdeniz University Hospital, Antalya, Turkey. Informed consent was obtained from all patients. Medical charts of all patients were reviewed, and data concerning the medical and infertility-related history, pelvic examination, treatment modalities and follow-up were recorded. The ethics committee of Akdeniz University Hospital approved the study according to the Good Clinical Practice guidelines of the International Conference on Harmonization and national regulations (11) 
Crude $\mathrm{OR}(95 \% \mathrm{Cl}) \quad$ Adjusted $\mathrm{OR}(95 \% \mathrm{Cl})$ P value $\mathrm{N}$

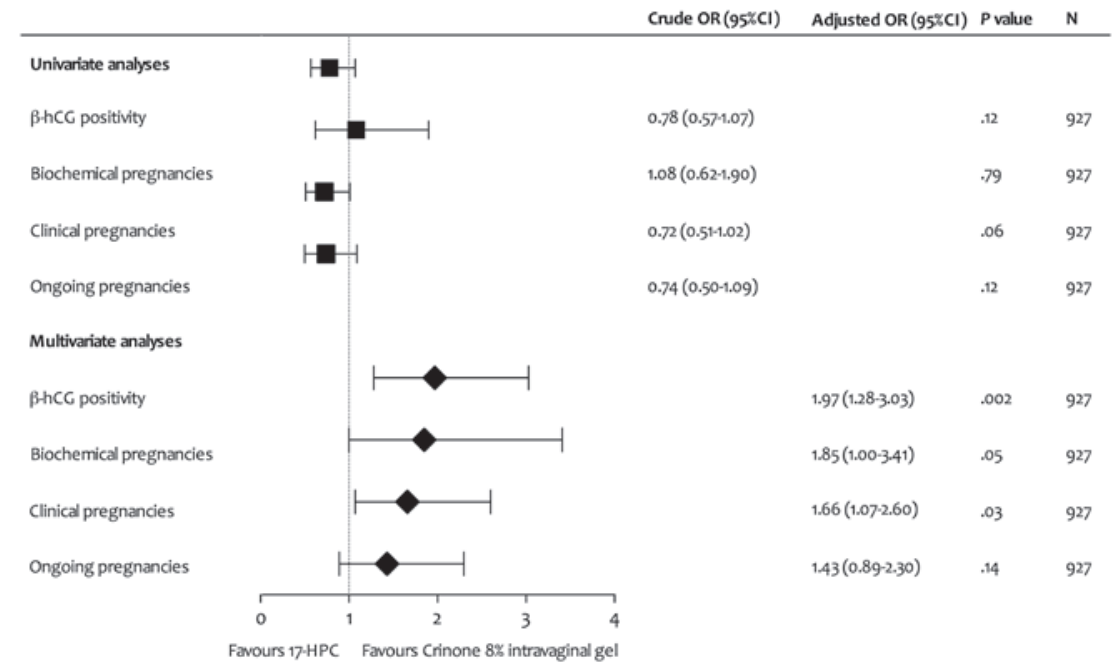

Figure 1. Univariate and multivariate analyses of dataset. OR, odds ratio; CI, confidence interval; 17-HPC, 17- $\alpha$-hydroxyprogesterone caproate; hCG, human chorionic gonadotropin.

Procedures. Controlled ovarian hyperstimulation $(\mathrm{COH})$ was applied according to the long protocol-GnRH analog or antagonist protocol (12). Oocyte pick-up (OPU) was performed $36 \mathrm{~h}$ after hCG injection. Starting from the night of the OPU, patients received IV or IM progesterone and slow oscillating transdermal oestrogen (Climara ${ }^{\circledR}$ Forte $7.8 \mathrm{mg}$; Schering German, Istanbul, Turkey) for LPS, until the 12th day after ET when pregnancy tests were performed. LPS was provided by the administration of $90 \mathrm{mg}$ /day IV progesterone (Crinone ${ }^{\circledR} 8 \%$ vaginal gel; Serono, Istanbul, Turkey) or $250 \mathrm{mg}$ IM 17- $\alpha$-hydroxyprogesterone caproate (17-HPC; Proluton depot ${ }^{\circledR}$ ampules; Bayer Schering, Istanbul, Turkey) every 3 days. Serum $\beta$-hCG was analyzed on the 12 th day after ET. Endometrial thickness was measured on the day of hCG administration.

Study outcomes. The primary outcome of the study was on-going pregnancy rate. Secondary endpoints included $\beta$-hCG positivity, biochemical pregnancy and clinical pregnancy rates. Biochemical pregnancy was defined as the absence of clinical and sonographical evidence of pregnancy despite positive $\beta$-hCG values ( $>10 \mathrm{mIU} / \mathrm{ml})$. Clinical pregnancies were exclusive of biochemical and ectopic pregnancies and required a detectable intrauterine gestational sac on ultrasound examination. On-going pregnancies were defined by the presence of intrauterine embryonic heart activity, as determined by transvaginal ultrasonography.

Statistical methods. Demographic and clinical characteristics are reported with descriptive analysis. Normality of data distribution was assessed by the Shapiro-Wilk test. All continuous variables were dichotomized by means of median values. Mann-Whitney U test, Student's t-test, and Chi-square tests were used for univariate comparisons. Variables with a $\mathrm{P}<0.05$ in univariate analysis were included in the logistic regression analysis. A P-value of $<0.05$ was required to reject the null hypothesis. Effects on pregnancy rates were reported by adjusted odds ratios (ORs) and 95\% confidence intervals (CIs). Post hoc power analysis revealed an OR of 0.5 with a power of
$100 \%$ and an overall two-sided type I error of 5\%, with inclusion of a total of 952 women in a two-sided Wald test. All data management and analyses were performed using Stata version 11 (Stata Corp., College Station, TX, USA) and Prism version 5.0 for Mac OSX (GraphPad software Inc., La Jolla, CA, USA).

\section{Results}

A total of 952 women in their first IVF-ET cycles were included in the study. The IM 17-HPC group consisted of 632 women $(66.4 \%)$ and the other $320(33.6 \%)$ patients received IV Crinone $8 \%$ gel. A total of 25 cycles were cancelled: 15 (2.4\%) cycles in 17-HPC group and $10(3.1 \%)$ cycles in the Crinone group $(\mathrm{P}=0.49)$. Thus, final analyses were performed in a total of 927 patients, including 617 patients in the 17-HPC group and 310 in the Crinone group. The main clinical and demographic data of the patients are shown in Table I.

The median age was 32 years (range, $20-46$ years). The 17-HPC group was older (32 vs. 31 years of age, $\mathrm{P}=0.003$ ); had higher basal FSH (6.6 vs. $6.4 \mathrm{IU} / 1, \mathrm{P}=0.01)$, basal estradiol (E2) [305 pmol/l (83 pg/ml) vs. $283 \mathrm{pmol} / 1$ (77 pg/ml), P<0.001], and serum E2 levels on the day of hCG administration $[13,928 \mathrm{pmol} / 1$ (3,794 pg/ml) vs. 12,817 pmol/l (3,492 pg/ml), $\mathrm{P}<0.001]$; had a longer duration of gonadotropin stimulation (12.24 vs. 11.90 days, $\mathrm{P}<0.001)$, higher total dose of gonadotropins $(3,700$ vs. $3,413 \mathrm{IU}, \mathrm{P}<0.001)$ and thicker endometrial thickness ( 8.3 vs. $7.6 \mathrm{~mm}, \mathrm{P}<.001)$. The median numbers of retrieved oocytes and transferred embryos were also higher in the 17-HPC group ( $\mathrm{P}=0.03$ and $\mathrm{P}<0.001$, respectively). The groups were comparable for the remaining demographic characteristics including infertility periods, infertility etiology and IVF indications. The most frequent IVF-ET indication in the two groups was ovulatory dysfunction (Table I).

There were no statistically significant differences between the Crinone and 17-HPC groups with respect to total $\beta$-hCG positivity, biochemical pregnancy, clinical pregnancy and on-going pregnancy rates in univariate analyses (Fig. 1). In multivariate regression analysis, the use of Crinone was associated with higher $\beta$-hCG positivity and clinical pregnancy 
Table I. Characteristics of IVF groups.

\begin{tabular}{|c|c|c|c|}
\hline Variables & IM 17-HPC (n=632) & Crinone $8 \%$ gel $(n=320)$ & P-value \\
\hline Age, years & & & 0.003 \\
\hline Median & 32 & 31 & \\
\hline Interquartile range & $29-36$ & $28-35$ & \\
\hline Duration of infertility, years & & & 0.14 \\
\hline Median & 7 & 6 & \\
\hline Interquartile range & $5-9$ & $4-9$ & \\
\hline Etiology of infertility, n (\%) & & & 0.56 \\
\hline Primary & $561(88.8)$ & $288(90.0)$ & \\
\hline Secondary & $71(11.2)$ & $32(10.0)$ & \\
\hline IVF indications, n (\%) & & & 0.06 \\
\hline Male factor & $81(12.8)$ & $35(10.9)$ & \\
\hline Tubal factor & $102(16.1)$ & $46(14.4)$ & \\
\hline Ovulatory dysfunction & $216(34.2)$ & $137(42.8)$ & \\
\hline Endometriosis & $76(12.0)$ & $31(9.7)$ & \\
\hline Male and female factor & $13(2.1)$ & $14(4.4)$ & \\
\hline Advanced maternal age & $30(4.8)$ & $10(3.1)$ & \\
\hline Unexplained & $93(14.7)$ & $41(12.8)$ & \\
\hline Other & $21(3.3)$ & $6(1.9)$ & \\
\hline Cancelled cycles, n (\%) & $15(2.4)$ & $10(3.1)$ & 0.49 \\
\hline Basal FSH, IU/l & & & 0.01 \\
\hline Median & 6.6 & 6.4 & \\
\hline Interquartile range & $5.4-8.0$ & $4.2-7.8$ & \\
\hline Basal E2, pmol/1 (pg/ml) & & & $<0.001$ \\
\hline Median & $305(83.0)$ & $283(77.0)$ & \\
\hline Interquartile range & $268-330(73.0-90.0)$ & $202-340(55.0-93.0)$ & \\
\hline Duration of gonadotropin stimulation, days & & & $<0.001$ \\
\hline Median & 12.24 & 11.90 & \\
\hline Standard deviation & 1.08 & 1.45 & \\
\hline Number of retrieved oocytes & & & 0.03 \\
\hline Median & 18 & 17 & \\
\hline Interquartile range & $15-21$ & $13-21$ & \\
\hline Number of transferred embryos & & & $<0.001$ \\
\hline Median & 3 & 3 & \\
\hline Interquartile range & $3-3$ & $2-3$ & \\
\hline E2 levels ${ }^{\mathrm{a}}, \mathrm{pmol} / \mathrm{l}(\mathrm{pg} / \mathrm{ml})$ & & & $<0.001$ \\
\hline Median & $13928(3794)$ & $12817(3492)$ & \\
\hline Interquartile range & $11237-16988(3061-4628)$ & $10336-15695(2816-4276)$ & \\
\hline Total dose of gonadotropin, IU & & & $<0.001$ \\
\hline Median & 3700 & 3413 & \\
\hline Interquartile range & $3000-4375$ & $2750-4075$ & \\
\hline Endometrial thickness, $\mathrm{mm}$ & & & $<0.001$ \\
\hline Median & 8.3 & 7.6 & \\
\hline Interquartile range & $7.6-9.4$ & 7.1-8.4 & \\
\hline
\end{tabular}

IVF, in vitro fertilization; FSH, follicle-stimulating hormone; E2, estradiol; IM, intramuscular; 17-HPC, 17- $\alpha$-hydroxyprogesterone caproate; hCG, human chorionic gonadotropin. ${ }^{\mathrm{a}} \mathrm{E} 2$ levels on the day of hCG administration. 
rates $(\mathrm{OR}, 1.97 ; 95 \% \mathrm{CI}, 1.28-3.03 ; \mathrm{P}=0.002 ;$ and $\mathrm{OR}, 1.66$; $95 \%$ CI, 1.07-2.60; $\mathrm{P}=0.03$, respectively). There was a trend toward higher biochemical pregnancy rates favouring Crinone $8 \%$ IV gel (OR, 1.85; 95\% CI, 1.00-3.41; $\mathrm{P}=0.05$ ). However, no statistically significant difference was found in terms of on-going pregnancy rates between the groups (OR, 1.43; 95\% CI, 0.89-2.30; P=0.14; Fig. 1).

\section{Discussion}

This analysis shows that Crinone vaginal gel is associated with comparable pregnancy outcomes to IM progesterone, 17-HPC. To the best of our knowledge, this is the largest study comparing these two forms of luteal phase progesterone support in IVF.

Progesterones may be administered via the oral, vaginal, or IM routes for LPS following IVF-ET. Despite it being an easy-to-use form, oral progesterone support provides lower implantation rates than other forms of progesterone $(13,14)$. It has unpleasant side-effects, including nausea, fluid retention, sedation, drowsiness and other hypnotic effects as a result of metabolites generated by the first-pass effect $(15,16)$. At present, oral progesterone is not a preferred method for LPS following IVF-ET. IM progesterone in oil has higher rates of clinical and on-going pregnancies compared with placebo or oral forms of progesterone (17-19). However, the IM progesterone-in-oil form has also various side-effects, including serious inflammatory reactions, sterile abscesses and significant patient discomfort. These side-effects may last for long periods of time, even after the discontinuation of the drug (20).

17-HPC, a slow-release, long-acting derivative of progesterone, may hypothetically be regarded as a valid alternative to the IM progesterone-in-oil form with an advantage of reduced patient discomfort. It has been found to be comparable to the IM progesterone-in-oil form with respect to clinical or on-going pregnancy rates in a prospective randomized study (20). However, evidence regarding the equivalent efficacy between the two formulations is limited.

The most commonly used vaginal regimens include $600 \mathrm{mg}$ progesterone (200 $\mathrm{mg}$ three times a day) as an oil-in-capsule formulation and daily $90 \mathrm{mg}$ progesterone in a polycarbophil-containing bioadhesive gel form (Crinone $8 \%$ ). These formulations have similar pregnancy outcomes and minor side-effects in LPS (21-23).

Currently, standard progesterone administration during LPS is provided by either the vaginal (as an oil-in-capsule or bioadhesive gel form) or IM route (50 mg a day). Previously, a number of studies sought to evaluate the optimal route of progesterone administration during LPS (24-27). Based on a meta-analysis of nine prospective randomized controlled trials that included a total of 1,620 individuals, vaginal and IM in-oil forms of progesterone applied during LPS are comparable in terms of clinical pregnancy rate ( 34.2 vs. $36.3 \%$; OR, 0.91 ; 95\% CI, 0.74-1.13) and on-going pregnancy rate (25.3 vs. 26.5\%; OR, 0.94; 95\% CI, 0.71-1.26) (12). Overall, this meta-analysis and most of the prospective trials included support the results of univariate analysis in the current study. The only prospective study comparing 17-HPC with Crinone demonstrated superior efficacy with 17-HPC (28). Discrepancies between the results of our study and previous studies may be attributed to the method of dealing with confounding factors. Differences in random- ization strategies used in prospective studies and multivariate regression modelling, if any, in retrospective analyses are the main cause of heterogeneity in the results of various studies.

We conclude that LPS with IV progesterone gel in comparison with IM 17-HPC appears to be associated with better clinical pregnancy rates in IVF-ET cycles. However, this benefit is clinically irrelevant in terms of on-going pregnancy outcomes.

\section{References}

1. Practice Committee of American Society for Reproductive Medicine in collaboration with Society for Reproductive Endocrinology and Infertility: Progesterone supplementation during the luteal phase and in early pregnancy in the treatment of infertility: an educational bulletin. Fertil Steril 90 (Suppl): S150-S153, 2008.

2. Fatemi HM, Popovic-Todorovic B, Papanikolaou E, Donoso P and Devroey P: An update of luteal phase support in stimulated IVF cycles. Hum Reprod Update 13: 581-590, 2007.

3. Penzias AS: Luteal phase support. Fertil Steril 77: 318-323, 2002.

4. Smitz J, Erard P, Camus M, et al: Pituitary gonadotrophin secretory capacity during the luteal phase in superovulation using GnRH-agonists and HMG in a desensitization or flare-up protocol. Hum Reprod 7: 1225-1229, 1992.

5. Albano C, Grimbizis G, Smitz J, et al: The luteal phase of nonsupplemented cycles after ovarian superovulation with human menopausal gonadotropin and the gonadotropin-releasing hormone antagonist Cetrorelix. Fertil Steril 70: 357-359, 1998.

6. Daya S and Gunby JL: Luteal phase support in assisted reproduction cycles. Cochrane Database Syst Rev 3: CD004830, 2004.

7. Levine H: Luteal support in IVF using the novel vaginal progesterone gel Crinone 8\%: results of an open-label trial in 1184 women from 16 US centers. Fertil Steril 74: 836-837, 2000.

8. Penzias AS and Alper MM: Luteal support with vaginal micronized progesterone gel in assisted reproduction. Reprod Biomed Online 6: 287-295, 2003.

9. Miles RA, Paulson RJ, Lobo RA, Press MF, Dahmoush L and Sauer MV: Pharmacokinetics and endometrial tissue levels of progesterone after administration by intramuscular and vaginal routes: a comparative study. Fertil Steril 62: 485-490, 1994.

10. Zarutskie PW and Phillips JA: A meta-analysis of the route of administration of luteal phase support in assisted reproductive technology: vaginal versus intramuscular progesterone. Fertil Steril 92: 163-169, 2009.

11. ICH Topic E 6 (R1) Guideline for Good Clinical Practice. In: ICH Harmonised Tripartite Guideline. Version of July 1996 including post step errata of July 2002. European Medicines Agency, London, UK, 2002. Available from: http://www.emea.europa.eu/ pdfs/human/ich/013595en.pdf. Accessed April 3, 2013.

12. Arslan M, Bocca S, Mirkin S, Barroso G, Stadtmauer L and Oehninger S: Controlled ovarian hyperstimulation protocols for in vitro fertilization: two decades of experience after the birth of Elizabeth Carr. Fertil Steril 84: 555-569, 2005.

13. Friedler S, Raziel A, Schachter M, Strassburger D, Bukovsky I and Ron-El R: Luteal support with micronized progesterone following in-vitro fertilization using a down-regulation protocol with gonadotropin-releasing hormone agonist: a comparative study between vaginal and oral administration. Hum Reprod 14: 1944-1948, 1999.

14. Pouly JL, Bassil S, Frydman R, et al: Luteal support after in-vitro fertilization. Crinone $8 \%$, a sustained release vaginal progesterone gel versus Utrogestan, an oral micronized progesterone. Hum Reprod 11: 2085-2089, 1996.

15. Arafat ES, Hargrove JT, Maxson WS, Desiderio DM, Wentz AC and Andersen RN: Sedative and hypnotic effects of oral administration of micronized progesterone may be mediated through its metabolites. Am J Obstet Gynecol 159: 1203-1209, 1998.

16. Maxon W and Hargrove JT: Bioavailability of oral micronized progesterone. Fertil Steril 44: 622-626, 1985.

17. Artini PG, Volpe A, Angioni S, Galassi MC, Battaglia C and Genazzani AR: A comparative randomized study of three different progesterone support of the luteal phase following IVF/ET programme. J Endocrinol Invest 18: 51-56, 1995. 
18. Abate A, Perino M, Abate FG, Brigandì A, Costabile L and Manti F: Intramuscular versus vaginal administration of progesterone for luteal phase support after in vitro fertilization and embryo transfer: a comparative study. Clin Exp Obstet Gynecol 26: 203-206, 1999.

19. Abate A, Brigandi A, Abate FG, Manti F, Unfer V and Perino M: Luteal phase support with 17 alpha-hydroxyprogesterone versus unsupported cycles in in vitro fertilization: a comparative randomized study. Gynecol Obstet Invest 48: 78-80, 1999.

20. Costabile L, Gerli S, Manna C, Rossetti D, Di Renzo GC and Unfer V: A prospective randomized study comparing intramuscular progesterone and $17 \alpha$-hydroxy progesterone caproate in patients undergoing in vitro fertilization-embryo transfer cycles. Fertil Steril 76: 394-396, 2001.

21. Ludwig M, Schwartz P, Babahan B, et al: Luteal phase support using either Crinone $8 \%$ or Utrogest: results of a prospective randomized study. Eur J Obstet Gynecol Reprod Biol 103: 48-52, 2002.

22. Ng EH, Miao B, Cheung W and Ho PC: A randomized comparison of side effects and patient inconvenience of two vaginal progesterone formulations used for luteal support in in vitro fertilization cycles. Eur J Obstet Gynecol Reprod Biol 111: 50-54, 2003

23. Kimzey LM, Gumowski J, Merriam GR, Grimes GJ Jr and Nelson LM: Absorption of micronized progesterone from a nonqualifying vaginal cream. Fertil Steril 56: 995-996, 1991.
24. Propst AM, Hill JA, Ginsburg ES, Hurwitz S, Politch J and Yanushpolsky EH: A randomized study comparing Crinone $8 \%$ and intramuscular progesterone supplementation in in vitro fertilization-embryo transfer cycles. Fertil Steril 76: 1144-1149, 2001.

25. Perino M, Brigandi FG, Abate FG, Costabile L, Balzano E and Abate A: Intramuscular versus vaginal progesterone in assisted reproduction: a comparative study. Clin Exp Obstet Gynecol 24: 228-231, 1997.

26. Smitz J, Devroey P, Faguer B, Bourgain C, Camus M and Van Steirteghem AC: A prospective randomized comparison of intramuscular or intravaginal natural progesterone as a luteal phase and early pregnancy supplement. Hum Reprod 7: 168-175, 1992.

27. Damario MA, Goudas VT, Session DR, Hamit DG and Dumesic DA: Crinone 8\% vaginal progesterone results in lower implantation efficiency after IVF-ET. Fertil Steril 72: 830-836, 1999.

28. Unfer V, Casini ML, Costabile L, Gerli S, Baldini D and Di Renzo GC: $17 \alpha$-hydroxyprogesterone caproate versus intravaginal progesterone in IVF-embryo transfer cycles: a prospective randomized study. Reprod Biomed Online 9: 17-21, 2004. 